Proc. Estonian Acad. Sci. Eng., 2004, 10, 2, 110-122

\title{
Using photoplethysmographic signal for increasing the accuracy of indirect blood pressure measurement
}

\begin{abstract}
Ákos Jobbágy
Department of Measurement and Information Systems, Budapest University of Technology and Economics, p.o.b. 91, 1521 Budapest, Hungary; jobbagy@mit.bme.hu

Received 9 December 2003, in revised form 29 March 2004

Abstract. Automatic and semi-automatic blood pressure meters are widespread in home health monitoring. However, their results are not accurate and reproducible enough, the reliability of selfassessment is not satisfactory and medical doctors have reservations about their results. The aim of this study was to increase the accuracy and reproducibility of the indirect, cuff-based blood pressure measurement with the help of the photoplethysmographic (PPG) signal. The additional information gained from the PPG signal during slow inflation provides more accurate results than conventional indirect methods and assures that the cuff pressure only slightly (by less than $10 \mathrm{~mm}$ $\mathrm{Hg}$ ) exceeds the systolic pressure. Measuring the pulse wave transit time and its variation during slow inflation and deflation makes it possible to characterize the sympathetic control of the cardiovascular system and the rigidity of the brachial arteries. The PPG signal also indicates if the cuff is placed or inflated improperly. The method has been validated making 420 measurements on 51 subjects.
\end{abstract}

Key words: blood pressure measurement, photoplethysmographic signal, home health monitoring, reproducibility, rigidity of arteries.

\section{INTRODUCTION}

A single measurement does not give enough information to qualify the blood pressure of a person as normal or pathological. The blood pressure varies during the day. Variations $20-30 \mathrm{~mm} \mathrm{Hg}$ are not uncommon even for healthy subjects. The white-coat effect is also well known. Many of us have increased blood pressure at the doctor's office. Self-measurement of blood pressure at home eliminates the white-coat effect, makes possible measurements always at the same phase of the daily activities and promotes the devotion of the person 
involved to the health keeping process. Inaccurate devices prevent subjects from being motivated and impair the medical treatment. It is important to provide accurate blood pressure meters for self-monitoring.

The error rate of commercially available blood pressure meters has been investigated in $\left[{ }^{1,2}\right]$. Both the American Association for the Advancement of Medical Instrumentation (AAMI) and the British Hypertension Society (BHS) have published standards for grading sphygmomanometers. Both standards define the mercury sphygmomanometer as a reference device and allow substantial deviations. The best grade (A) in the BHS standard allows $40 \%$ of the results deviate from the reference by more than $5 \mathrm{~mm} \mathrm{Hg}, 15 \%$ of the results by more than $10 \mathrm{~mm} \mathrm{Hg}$ and $5 \%$ of the results by more than $15 \mathrm{~mm} \mathrm{Hg}$. A clinical review of a number of presently used blood pressure meters revealed that the majority of the devices did not meet the standards $\left[^{3}\right]$. Guidelines are available for self-monitoring the blood pressure $\left[{ }^{4}\right]$.

The oscillometric method is used in the majority of presently available devices applicable for home use. These devices are simple to use but not accurate enough.

The aim of this study is to show that the PPG signal, recorded at the fingertip, may increase the accuracy by providing extra information related to the blood pressure. The PPG signal helps to measure the systolic pressure directly unlike the oscillometric method that measures the mean pressure and gives only an estimate of the systolic and diastolic pressures. The additional information can also be used to detect if the cuff is wrapped up and inflated correctly.

During cuff-based blood pressure measurement, the occlusion, applied by the cuff, changes the biomechanical properties of the brachial artery. This means that the measurement changes the pressure values to be measured. Its consequences have also been investigated.

\section{MATERIALS AND METHODS}

\subsection{The oscillometric method}

The oscillometric method is used in the majority of present-day cuff-based (semi-)automatic blood pressure meters. The method requires neither extra sensor nor operator expertise to detect the equality of the cuff pressure to different levels of arterial pressure (systolic, diastolic, and mean). The primary measured parameter is the arterial mean pressure, indicated by the maximal oscillometric amplitude $\left.{ }^{5}\right]$.

The calculation of systolic and diastolic pressure values is based mainly on the amplitudes of the pressure oscillations. The ratio of amplitudes (SM = systolic/mean, $\mathrm{DM}=$ diastolic/mean) were determined by supposing average values for human physiological parameters. When the cuff is on the upper arm, $\mathrm{SM}=0.4-0.6$ and $\mathrm{DM}=0.70-0.85$ have been reported. Theoretical analysis and a model for arterial mechanics have been proposed in $\left[{ }^{6}\right]$ with $\mathrm{SM}=0.593$ and 
$\mathrm{DM}=0.717$. The parameters SM and DM show little variation over the normal range of blood pressure. However, at high values of systolic pressure SM should be lowered and at low values of diastolic pressure DM should be lowered. The paper $\left[{ }^{7}\right]$ analyses different physiological parameters that influence SM and DM.

Our detailed analysis revealed that the oscillation amplitude vs. cuff pressure curves (and consequently SM and DM) vary from measurement to measurement even for the same person tested at rest. The actual values of these parameters are unknown during an oscillometric blood pressure measurement. Consequently, the oscillometric blood pressure meters give only an estimate for the arterial systolic and diastolic pressures. The derivative oscillometry $\left[{ }^{5}\right]$ determines the systolic and diastolic pressures based on the change of oscillation amplitudes during deflation. The accuracy is reported to be about the same as that of conventional oscillometry.

New oscillometric blood pressure measuring devices take into account not only the amplitude but also the shape of oscillometric pulses. The application of shape evaluation decreases the number of results with unacceptable $(>15 \%)$ error.

\subsection{The PPG signal as an aid}

The PPG signal $\left[{ }^{8,9}\right]$ indicates volume changes in the blood vessels. The occlusion of the brachial artery influences the pulsation in the PPG signal measured at the fingertip.

Figure 1 shows the pressure - time function of an upper arm cuff and the PPG signal taken from the fingertip of a young healthy subject at rest. The cuff of the automatic meter was inflated slowly. The systolic pressure $(117 \mathrm{~mm} \mathrm{Hg})$ displayed

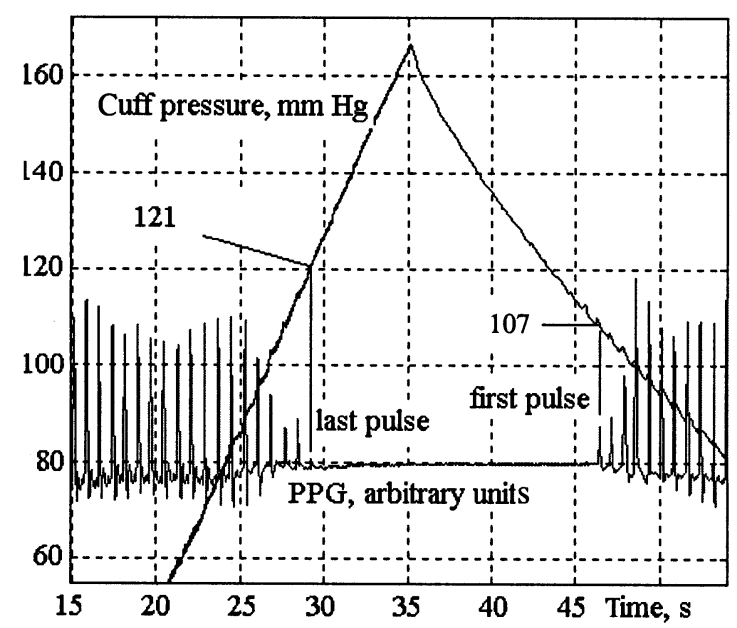

Fig. 1. Cuff pressure and PPG signal at the fingertip during measurement with an upper arm cuff. 
by the meter (OMRON M4) correlates well with the cuff pressure measured during inflation when the last pulse appeared in the PPG signal.

During deflation it was found that when the pressure of the upper arm cuff decreased below the systolic pressure, the first opening and the following 1-2 openings of the artery remained undetected in the PPG signal taken at the fingertip. This can also be seen in Fig. 1. The cuff pressure is $107 \mathrm{~mm} \mathrm{Hg}$ when the first pulse in the PPG signal reappears. It is for $14 \mathrm{~mm} \mathrm{Hg}$ less than the cuff pressure when the last pulse in the PPG signal was present during slow inflation. When the cuff was inflated slowly, pulses in the PPG signal taken from the fingertip were present until the cuff pressure exceeded the systolic pressure.

The PPG signal can be measured on the upper arm; paper $\left[{ }^{10}\right]$ suggests to use wavelength $560 \mathrm{~nm}$ (green) to increase the signal/noise ratio. The pattern of hand arteries varies with subjects. Six main types of hand arteries have been defined in $\left[{ }^{11}\right]$. It is not possible to designate an anatomical landmark point on the hand to record the PPG signal reliably for everybody. The PPG signal was recorded simultaneously also with a wrist cuff meter. No place was found on the palm close to the cuff where pulses in the PPG signal appeared during deflation earlier than in the PPG signal at the fingertip.

\subsection{Pulse wave velocity}

Pulse wave velocity (PWV) is taken as an average over the distance from the heart to the fingertip. The PWV can be calculated by recording the ECG and PPG signals. Progressing through the arteries, PWV depends also on blood pressure. Many attempts have been made to make use of PWV during the blood pressure measurement. Based on PWV, the blood pressure variation can be estimated even without using a cuff $\left[{ }^{12-16}\right]$ :

$$
\begin{gathered}
v=\frac{L}{\Delta T_{\mathrm{PT}}}=\sqrt{\frac{E h}{\rho d}}, \\
E=E_{0} \mathrm{e}^{a P}, \\
P=\frac{1}{a}\left[\ln \left(\frac{L^{2} \rho d}{E_{0} h}\right)-2 \ln \left(\Delta T_{\mathrm{PT}}\right)\right] .
\end{gathered}
$$

Here $P$ is blood pressure, $v$ is pulse wave velocity, $E$ is the Young modulus of arterial wall ( $E_{0}$ is its value at $\left.P=0\right), h$ is the thickness and $d$ the inner radius of the artery, $\rho$ is blood density, $a$ is a constant, $L$ is the distance between the heart and the fingertip and $\Delta T_{\mathrm{PT}}$ is the pulse transit time. The time delay between the ECG and the PPG signal, $\Delta T_{\mathrm{EP}}$, is the sum of the pre-ejection time, $\Delta T_{\mathrm{PE}}$, and the pulse transit time, $\Delta T_{\mathrm{PT}}$ 


$$
\Delta T_{\mathrm{EP}}=\Delta T_{\mathrm{PE}}+\Delta T_{\mathrm{PT}} .
$$

The relation between the local pressure and flow in the artery is described in $\left[{ }^{17}\right]$. Since $\Delta T_{\mathrm{PT}}$ cannot be measured easily, $\Delta T_{\mathrm{EP}}$ is used instead.

The parameter $\Delta T_{\mathrm{EP}}$ is influenced also by factors other than blood pressure. This would cause substantial error if the blood pressure were estimated only on the basis of $\Delta T_{\mathrm{EP}}$. Paper $\left[{ }^{13}\right]$ suggests intermittent calibration with a cuff-based meter in every 5 minutes. It is shown that very low frequency (VLF) fluctuations in the PPG signal (and consequently in $\Delta T_{\mathrm{EP}}$ ) originate in the activity of the sympathetic nervous system $\left[{ }^{18}\right]$. When the PPG signal is taken from both hands, the effect of the VLF fluctuations in $\Delta T_{\mathrm{EP}}$ can be reduced [ $\left.{ }^{19}\right]$. This helps usually, but not always, to determine the diastolic pressure based on $\Delta T_{\mathrm{EP}}$. Paper $\left[{ }^{20}\right]$ suggests using the PWV as an indicator of the state of the arteries.

The PWV can also be used to characterize the arterial distensibility. Paper $\left[{ }^{21}\right]$ shows that the time delay between the ECG R-peak and the PPG pulse arrival to the toe and also the difference in the transit time of the blood pressure pulses between the toe and finger decrease with age but do not depend on the diastolic pressure. Our measurements show that both the initial value (completely deflated cuff) and the increase in $\Delta T_{\mathrm{EP}}$ during a cuff-based blood pressure measurement is greater in senior (50-60 year old) males than in the young (22-25) ones (monitoring the PPG signal at the fingertip). The change in the transit time, as a function of cuff pressure, is different during inflation and deflation. The reason is that the occlusion results in changes of the biomechanical properties of the arteries.

\subsection{Subjects and experimental protocol}

The number of subjects tested in the course of the reported experimental research work was 51 including 43 young (22-26 years old) and 8 senior (40-61 years old) subjects. There were 3 young and 2 senior female subjects in the tested group. The subjects had no known cardiovascular disease. Altogether 420 recordings were taken.

Commercially available automatic blood pressure monitors OMRON MX3 (with wrist cuff) and OMRON M4 (with upper arm cuff) were used. By regulating the motor control voltage, the inflation rate of the upper arm cuff could be set to $3-5(\mathrm{~mm} \mathrm{Hg}) / \mathrm{s}$ for the tests. The cuff pressure, PPG at the fingertip and Einthoven lead IECG were measured in parallel to analyse the effect of cuff pressure on the PPG signal and on the delay between the ECG and the PPG signal, $\Delta T_{\mathrm{EP}}$.

To test the effect of the duration of total occlusion of the left brachial artery, the maximum cuff pressure of an OMRON M4 meter was set for $20-90 \mathrm{~mm} \mathrm{Hg}$ higher than the estimated systolic value. 


\subsection{The measurement set-up}

The measurement set-up was built around a PCL-818 (Advantech Co. Ltd.) PC peripheral card. Four channels (cuff pressure, Einthoven lead IECG, two PPG signals) were recorded, 1000 samples/s each. The resolution of measuring the ECG and the PPG signals was 9 effective bits $\left(\Delta U / U_{\mathrm{pp}}\right)$. The cuff pressure was measured with a resolution of $0.05 \mathrm{~mm} \mathrm{Hg}$. This high resolution was assured by measuring the average time period of 512 cycles instead of the output frequency of the pressure sensor.

\section{RESULTS}

Figure 2 shows the result of 59 measurements taken from 14 healthy subjects (from 22 to 52 year old males) using the OMRON MX3 meter. In the majority of measurements the first pulse in the PPG signal during deflation appeared at a higher cuff pressure than the systolic pressure reported by the meter.

When the cuff is on the upper arm, the first opening of the brachial artery during deflation may remain undetected in the PPG signal taken at the fingertip. Figure 3 shows the results of 47 measurements.

The time delay between the first opening of the brachial artery and the first pulse detected in the PPG signal at the fingertip depends on the duration of the total occlusion of the artery. Figure 4 shows the results for four subjects. Four or

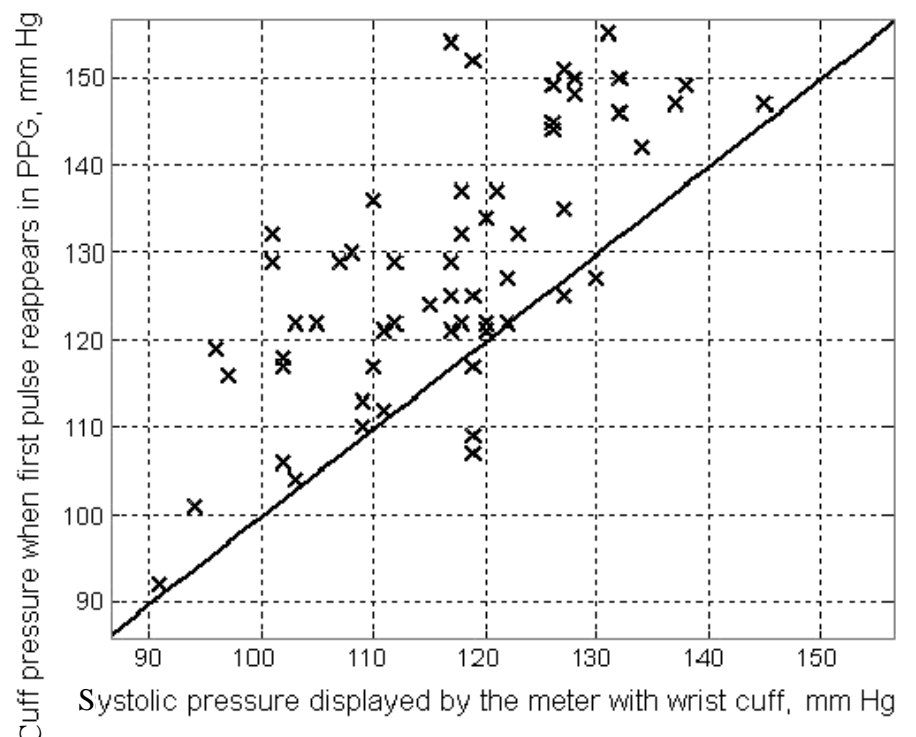

Fig. 2. Cuff pressure when the first pulse appeared in the PPG signal vs. systolic blood pressure displayed by the meter with a wrist cuff. 
five measurements were completed on each subject with 5-minute pauses. The longer is the total occlusion, the longer is the time delay.

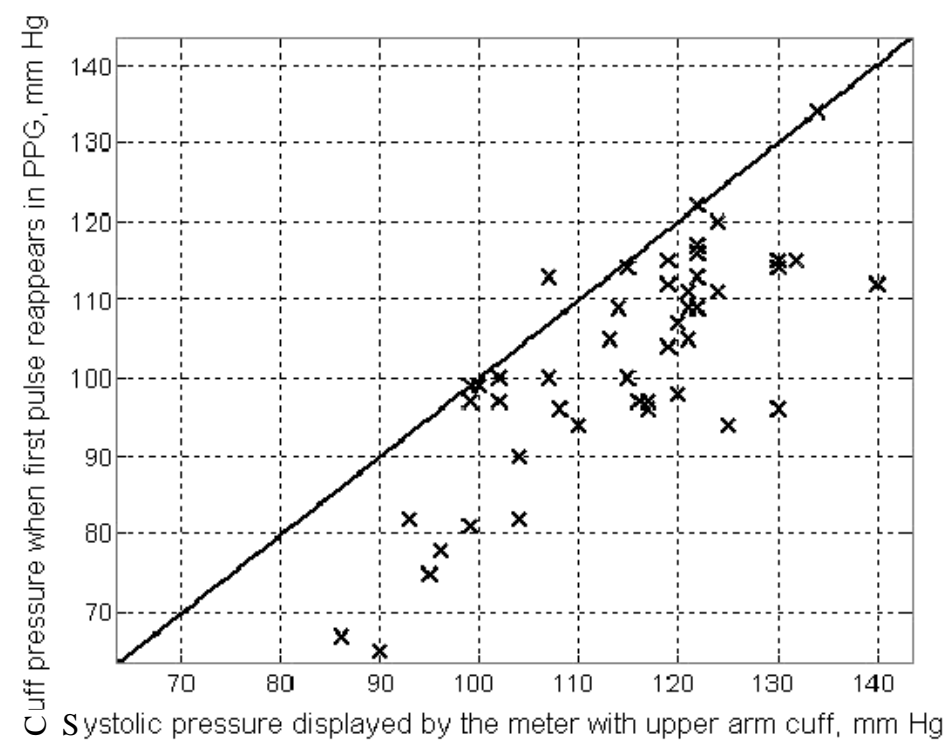

Fig. 3. Cuff pressure when the first pulse reappeared in the PPG signal vs. systolic blood pressure displayed by the meter with an upper arm cuff.

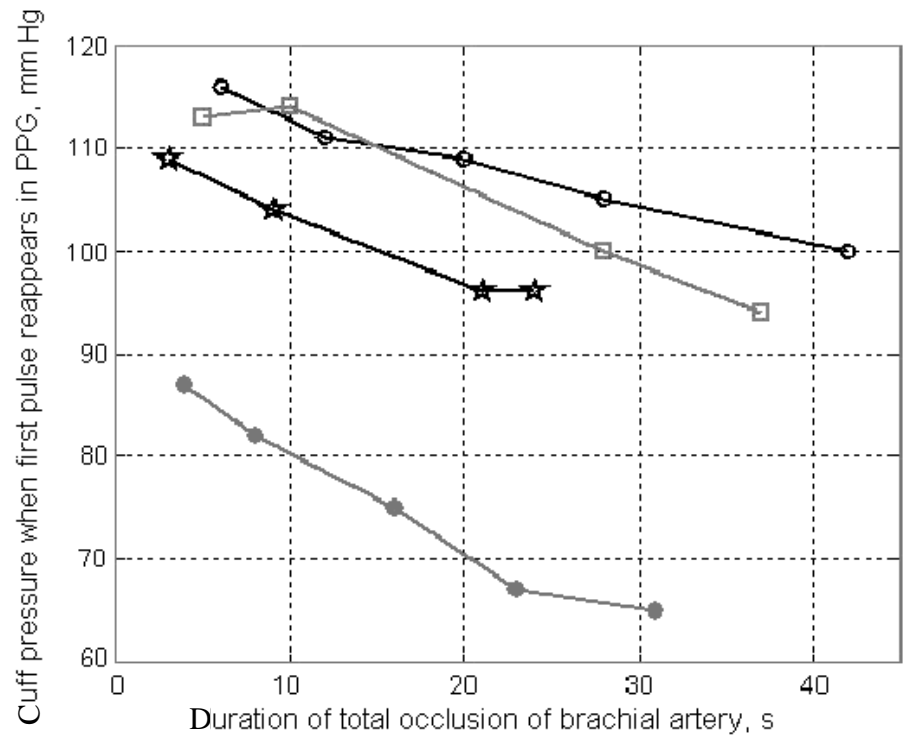

Fig. 4. Cuff pressure when first pulse reappears in PPG vs. duration of the total occlusion of the brachial artery; measurement series of four subjects. 
The PPG signal taken from the fingertip can be used to detect the systolic pressure if the upper arm cuff is inflated slowly. The cuff pressure when the last pulse appears in the PPG signal is recommended to be taken as the systolic pressure. Figure 5 shows the correlation between the systolic values calculated as described above and those displayed by the OMRON M4 meter. From 9 subjects 24 measurements were taken. The average inflation rate was $5(\mathrm{~mm} \mathrm{Hg}) / \mathrm{s}$; slower inflation rate would decrease the methodical error.

Amplitude variations in the PPG signal are present also when the cuff is completely deflated. When the cuff pressure exceeds the diastolic pressure, the amplitude and the slope of the pulse in the PPG signal decrease. The shape of the leading edge of the pulse also changes. The shape of the leading edge (and the change in it) is different from person to person. Figure 6 shows a typical change observed while testing a 44 year old male with slightly elevated diastolic pressure. The leading edges of the pulses in the PPG signal are drawn in the figure aligned at their maximum values. The occlusion of the brachial artery, even if it lasts for only a fraction of the heart cycle, results in the elevation of the end-diastolic level of the PPG signal. The heart cycles can be divided into two groups according to the enddiastolic level of the PPG signal. If the cuff pressure is lower than the diastolic one, the end-diastolic level is lower. The two groups are formed on the basis of the cuff pressure. The highest pressure in the first group is $91 \mathrm{~mm} \mathrm{Hg}$ and the lowest cuff pressure in the second group is $95 \mathrm{~mm} \mathrm{Hg}$. In the first group the diastolic pressure is close to the highest cuff pressure. In case of the measurements shown in Fig. 6, the diastolic pressure is close to $91 \mathrm{~mm} \mathrm{Hg}$.

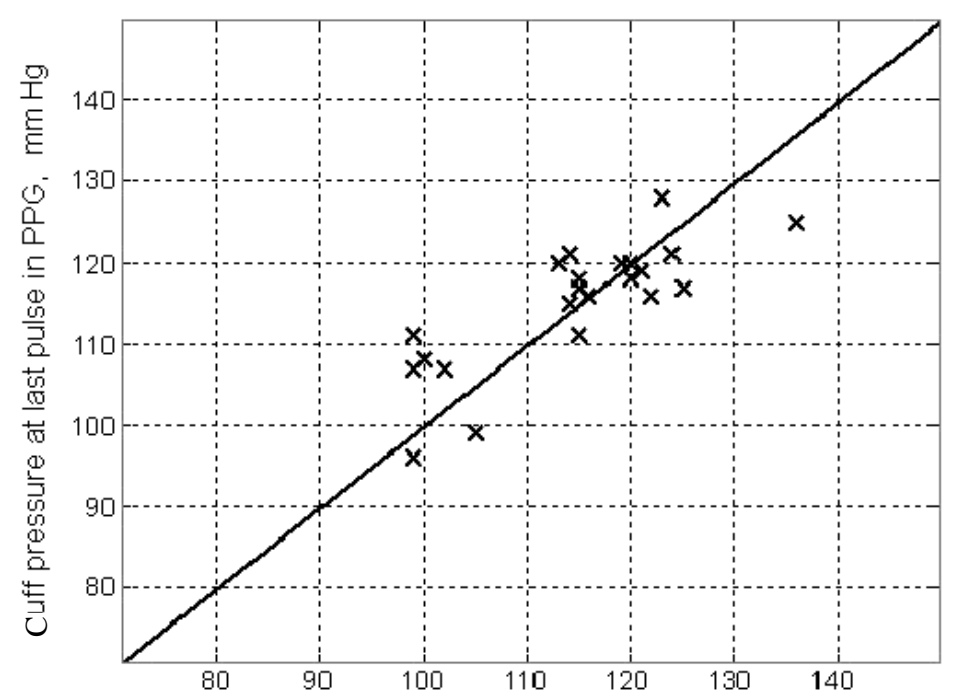

Systolic pressure displayed by the meter with upper arm cuff, $\mathrm{mm} \mathrm{Hg}$

Fig. 5. Cuff pressure when the last pulse was detected in the PPG signal during slow inflation vs. systolic blood pressure displayed by the meter with an upper arm cuff. 


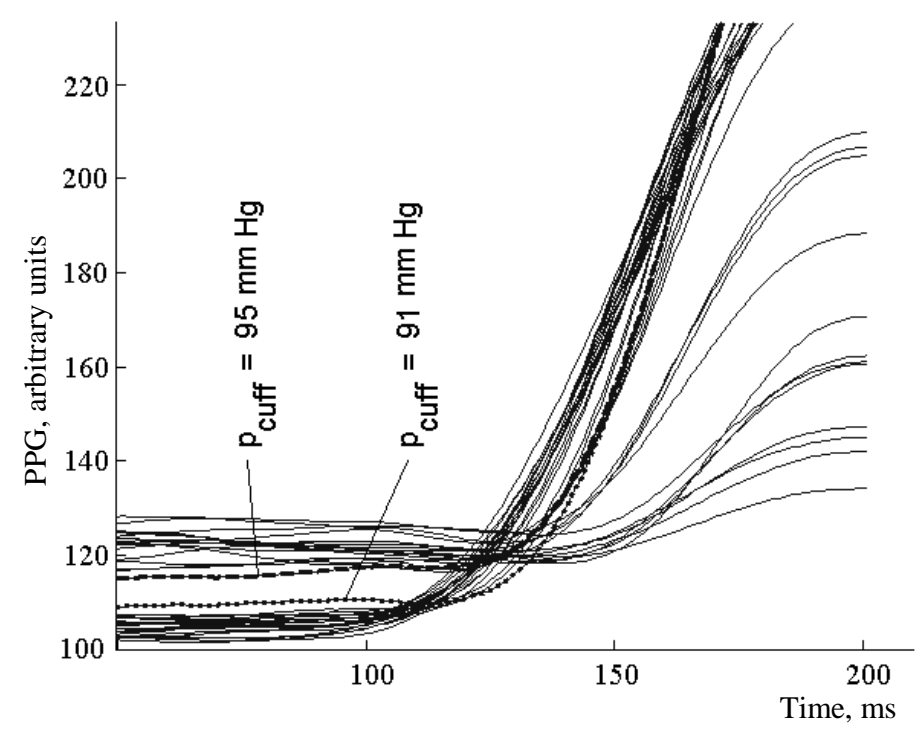

Fig. 6. Dependence of the end-diastolic level of the PPG signal on the cuff pressure.

During slow inflation, the steep decrease in the amplitude of the PPG, the change in the shape of the leading edge and the change in the end-diastolic level could always be observed when the upper arm cuff pressure was around the diastolic pressure.

Based on the PPG signal the proper placement and inflation of the cuff can be checked. When the cuff pressure is above the arterial systolic pressure, pulsation in the PPG signal should cease. In Fig. 7 pulses in the PPG signal are present dur-

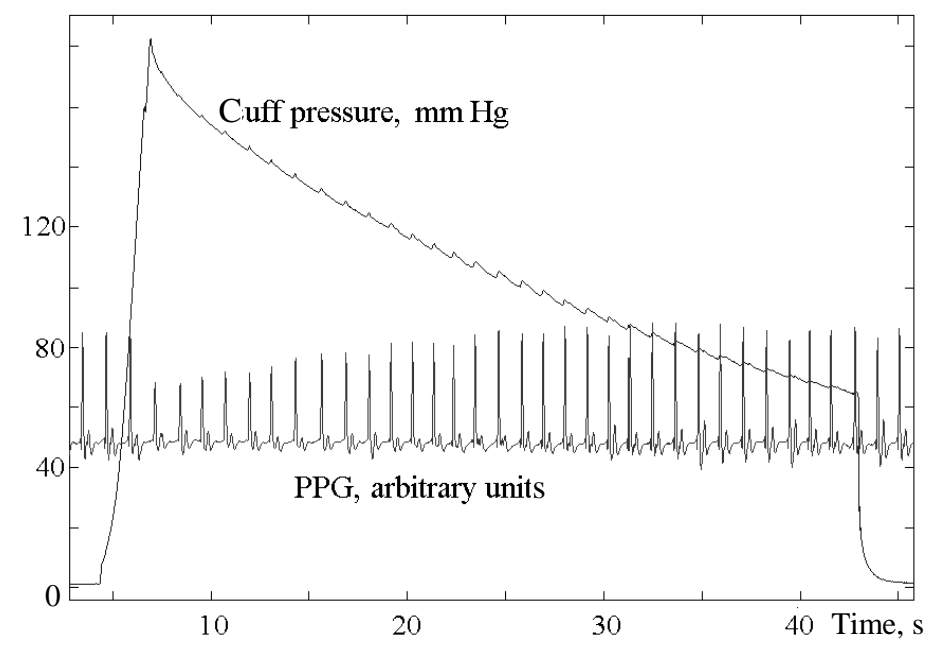

Fig. 7. Cuff pressure and PPG signal during measurement with a loosely wrapped up cuff. Note that pulses in the PPG signal do not disappear. 


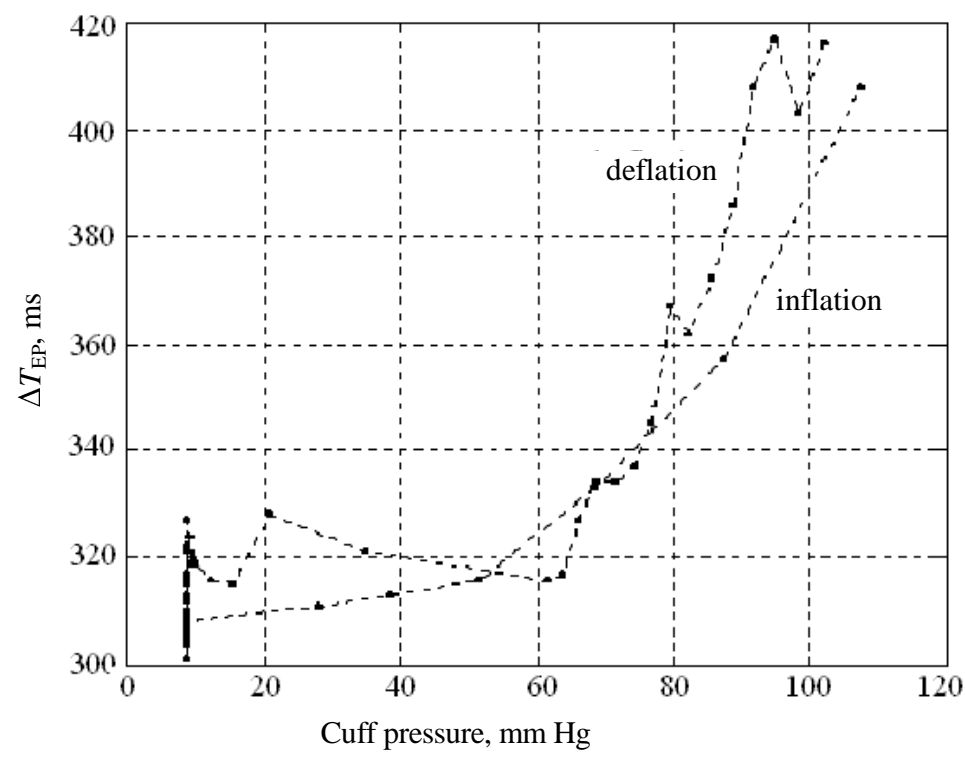

Fig. 8. The dependence of $\Delta T_{\mathrm{EP}}$ on the cuff pressure during slow inflation and deflation.

ing the whole measurement process. This indicates that the cuff was unable to occlude the brachial artery. However, based on the amplitudes of the oscillometric pulses the blood pressure meter was able to calculate the systolic blood pressure. Resulting from the improper occlusion, the meter displayed both the systolic and diastolic pressure by $15 \mathrm{~mm} \mathrm{Hg}(12 \%)$ above the real value.

The function $\Delta T_{\mathrm{EP}}\left(P_{\text {cuff }}\right)$ is different during inflation and deflation. Figure 8 shows $\Delta T_{\mathrm{EP}}$ measured during slow inflation and deflation. To cancel the effect of breathing, the 52 year old male held his breath during the measurement. The $\Delta T_{\mathrm{EP}}\left(P_{\text {cuff }}\right)$ curves and the difference during inflation and deflation help to characterize the rigidity of the arteries and the sympathetic control of the cardiovascular system.

\section{DISCUSSION}

The PPG signal helps to determine the systolic pressure during cuff-based indirect measurement though the exact relation between the arterial pulsation and the microcirculation is not known.

As the cuff occludes the artery, the systolic and diastolic pressures change. Monitoring $\Delta T_{\mathrm{EP}}$ before inflation and after deflation offers additional information and helps to compensate the distortion caused by the cuff. Breathing influences the systolic blood pressure. The resulting variation in the systolic pressure can be as high as $10 \mathrm{~mm} \mathrm{Hg}$. Monitoring $\Delta T_{\mathrm{EP}}$ for some breathing 
cycles offers the possibility of averaging the systolic values, increasing the reproducibility of the measurement.

Ambulatory 24-hour monitoring characterizes the blood pressure of a person much better than a few measurements. However, wearing the cuff for a day is uncomfortable; the inflation distorts the real values. A long-term monitoring of the pulse wave velocity offers a good compromise showing the trends in the systolic pressure without the need of a cuff.

Pulses in the PPG signal disappear when the cuff pressure is above the systolic value. If the cuff is not properly placed around the upper arm, pulses do not disappear in the PPG signal. Conventional oscillometric devices are unable to detect this erroneous situation and display a false result. Based on the PPG signal, the improper placement can be detected and the operator warned.

The function $\Delta T_{\mathrm{EP}}\left(P_{\text {cuff }}\right)$, recorded during slow inflation and deflation, shows the reaction of the sympathetic control of the tested person to the occlusion of the brachial artery. This is an important parameter for the assessment of the cardiovascular system. During inflation, $\Delta T_{\mathrm{EP}}$ increases as cuff pressure increases. The increase starts at low cuff pressure and in general there is no steep change in it when the cuff pressure equals the diastolic pressure. Our measurements show that the occlusion changes the biomechanical properties of the arteries. The function $\Delta T_{\mathrm{EP}}$ vs. cuff pressure is steeper during deflation than inflation for the majority of the tested persons $\left[{ }^{19}\right]$. Also, the almost linear change in the amplitude of the PPG signal around the diastolic pressure during inflation is usually not present during deflation. For this reason the systolic and diastolic pressures are suggested to be determined during slow inflation of the cuff.

\section{CONCLUSIONS}

The PPG signal is able to detect the pulse waves in the arterial blood flow. This makes it possible to detect the complete occlusion of the artery and consequently the systolic pressure. When the cuff pressure exceeds the diastolic pressure, the amplitude of the pulses decreases in the PPG signal and the shape of the leading edge of the pulses and the end-diastolic level also change. This helps to determine the diastolic pressure. The improperly placed or inflated cuff is easily detected by analysing the PPG signal. The sensor, needed for monitoring the PPG signal, can easily be added to contemporary (semi-)automatic blood pressure monitors. The described method increases accuracy and repeatability of automatic blood pressure meters with upper arm cuff.

\section{ACKNOWLEDGEMENT}

The Hungarian Ministry of Education supported the reported research work (OTKA grant No. T034948). Balázs Sántha and Tamás Turai helped in completing the measurements and evaluating the recorded data. 


\section{REFERENCES}

1. Shuler, C. L., Allison, N., Holcomb, S., Harlan, M., McNeill, J., Robinett, G., and Bagby, S. P. Accuracy of an automated blood pressure device in stable inpatients. Arch. Intern. Med., 1998, 158, 714-721.

2. Merrick, R. D., Olive, K. E., Hamdy, R. C., Landy, C., and Cancellaro, V. Factors influencing the accuracy of home blood pressure measurement. South. Med. J., 1997, 90, 1110-1114.

3. O'brien, E., Waeber, B., Parati, G., Staessen, J., and Myers, G. M. Blood pressure measuring devices: recommendations of the European Society of Hypertension. Br. Med. J., 2001, 322, 531-536.

4. Asmar, R. and Zanchetti, A. Guidelines for the use of self-blood pressure monitoring: a summary report of the first international consensus conference. J. Hypertension, 2000, 18, 493-508.

5. Drzewiecki, G. Noninvasive assessment of arterial blood pressure and mechanics. In Biomedical Engineering Handbook, CRC Press, Boca Raton, 1995, 1196-1211.

6. Drzewiecki, G., Hood, R., and Apple, H. Theory of the oscillometric maximum and the systolic and diastolic detection ratios. Ann. Biomed. Eng., 1994, 22, 88-96.

7. Ursino, M. and Cristalli, C. A mathematical study of some biomechanical factors affecting the oscillometric blood pressure measurement. IEEE Trans. Biomed. Eng., 1996, 43, 761-778.

8. Bhattacharya, J., Kanjilal, P. P., and Muralidhar, V. Analysis and characterization of photoplethysmographic signal. IEEE Trans. Biomed. Eng., 2001, 48, 5-11.

9. Lygouras, J. N., Tarchanidis, K. N., and Tsalides, Ph. G. A Digital optical-fibre finger blood volume meter. In Proc. IEEE Instrumentation and Measurement Technology Conference. Budapest, 2001, 648-653.

10. Lindberg, L. G. and Öberg, P. Å. Photoplethysmography, Part 2: Influence of light source wavelength. Med. Biol. Eng. Comput., 1991, 29, 48-54.

11. Platzer, W. Anatómia I. SH Atlasz. Springer Hungarica Kiadó kft, Budapest, 1996.

12. Jobbágy, Á. Photoplethysmographic signal aids indirect blood-pressure measurement. In Proc. Mediterranean Conference on Medical and Biological Engineering and Computing. Pula, Croatia, 2001, 262-264.

13. Chen, W., Kobayashi, T., Ichikawa, S., Takeuchi, Y., and Togawa, T. Continuous estimation of systolic blood pressure using the pulse arrival time and intermittent calibration. Med. Biol. Eng. Comput., 2000, 38, 569-574.

14. Lacković, I. and Šantić, A. Accuracy improvement of noninvasive finger blood pressure measurement. In Proc. IX Mediterranean Conference on Medical and Biological Engineering and Computing. Pula, Croatia, 2001, 281-284.

15. Lu, W., Li, H., Tao, S., Zhang, D., Jiang, Z., Cui, L., Tu, J., and Gou, D. Research on the main elements influencing blood pressure measurement by pulse wave velocity. Frontiers Med. Biol. Eng., 1992, 4, 189-199.

16. Pruett, J. D., Bourland, J. D., and Geddes, L. A. Measurement of pulse-wave velocity using a beat-sampling method. Annals Biomed. Eng., 1988, 16, 341-347.

17. Khir, A. W., O'Brien, A., Gibbs, J. S. R., and Parker, K. H. Determination of wave speed and wave separation in the arteries. J. Biomech., 2001, 34, 1145-1155.

18. Nitzan, M., Babchenko, A., Shemesh, D., and Alberton, J. Influence of thoracic sympathectomy on cardiac induced oscillations in tissue blood volume. Med. Biol. Eng. Comput., 2001, 39, 579-583.

19. Jobbágy, Á., Turai, T., and Sántha, B. Increasing the accuracy of oscillometric blood pressure measurement. In IFMBE Proc. 12th Nordic Baltic Conference on Biomedical Engineering and Medical Physics. Reykjavik, 2002, 24-25.

20. Hinrikus, H., Lass, J., Karai, D., and Tepner, I. Pulse wave parameters as indicators of the state of the arteries. In Proc. 2nd European Medical and Biological Engineering Conference. Vienna, 2002, 642-643.

21. Nitzan, M., Khanokh, B., and Slovik, Y. The difference in pulse transit time to the toe and finger measured by photoplethysmography. Physiol. Meas., 2002, 23, 85-94. 


\title{
Fotopletüsmograafilise signaali kasutamine vererõhu kaudse mõotmise täpsuse suurendamiseks
}

\begin{abstract}
Ákos Jobbágy
Automaatsed ja poolautomaatsed vererõhumõõturid on terviseseires väljaspool haiglat laialdast kasutust leidnud. Kahjuks on nende mõoturite näidud ebatäpsed ning mõõtetulemuste korratavus ja usaldatavus väike, mistõttu suhtuvad arstid nendesse teatud kahtlusega. Töö eesmärgiks oli fotopletüsmograafilise signaali kasutamine vererõhu kaudse, mansetti kasutava mõõtmise täpsuse ja korratavuse suurendamiseks. Täiendav info, mida fotopletüsmograafiline signaal annab pulsilaine leviaja ja selle variatsioonide kohta manseti aeglase täitumise ja tühjenemise käigus, iseloomustab kardiovaskulaarse süsteemi sümpaatilise regulatsiooni ja arterite jäikuse mõju mõõtetulemusele. Meetod võimaldab kindlaks teha ka manseti ebasobiva paigalduse. Kirjeldatud meetodit kontrolliti 420 mõõtmise käigus 51 katsealusel.
\end{abstract}

